\title{
Cardioprotection with halogenated gases: how does it occur?
}

\author{
This article was published in the following Dove Press journal: \\ Drug Design, Development and Therapy \\ 16 March 2017 \\ Number of times this article has been viewed
}

\author{
Jose Luis Guerrero- \\ Orriach ${ }^{1-3}$ \\ Juan Jose Escalona \\ Belmonte
}

Alicia Ramirez Fernandez'

Marta Ramirez Aliaga'

Manuel Rubio Navarro'

Jose Cruz Mañas'

'Department of Cardioanesthesiology, Virgen de la Victoria University Hospital, ${ }^{2}$ Instituto de Investigación Biomédica de Málaga (IBIMA), ${ }^{3}$ Department of Pharmacology and Pediatrics, University of Malaga, Malaga, Spain
Correspondence: Jose Luis GuerreroOrriach; Marta Ramirez Aliaga Department of Cardioanesthesiology, Virgen de la Victoria University Hospital, University Campus Teatinos, Malaga 29010, Spain

Email guerreroorriach@gmail.com; martaram85@hotmail.com

\begin{abstract}
Numerous studies have studied the effect of halogenated agents on the myocardium, highlighting the beneficial cardiac effect of the pharmacological mechanism (preconditioning and postconditioning) when employed before and after ischemia in patients with ischemic heart disease. Anesthetic preconditioning is related to the dose-dependent signal, while the degree of protection is related to the concentration of the administered drug and the duration of the administration itself. Triggers for postconditioning and preconditioning might have numerous pathways in common; mitochondrial protection and a decrease in inflammatory mediators could be the major biochemical elements. Several pathways have been identified, including attenuation of NFKB activation and reduced expression of TNF $\alpha$, IL-1, intracellular adhesion molecules, eNOS, the hypercontraction reduction that follows reperfusion, and antiapoptotic activating kinases (Akt, ERK1/2). It appears that the preconditioning and postconditioning triggers have numerous similar paths. The key biochemical elements are protection of the mitochondria and reduction in inflammatory mediators, both of which are developed in various ways. We have studied this issue, and have published several articles on cardioprotection with halogenated gases. Our results confirm greater cardioprotection through myocardial preconditioning in patients anesthetized with sevoflurane compared with propofol, with decreasing levels of troponin and N-terminal brain natriuretic peptide prohormone. The difference between our studies and previous studies lies in the use of sedation with sevoflurane in the postoperative period. The results could be related to a prolonged effect, in addition to preconditioning and postconditioning, which could enhance the cardioprotective effect of sevoflurane in the postoperative period. With this review, we aim to clarify the importance of various mechanisms involved in preconditioning and postconditioning with halogenated gases, as supported by our studies.
\end{abstract}

Keywords: sevoflurane, preconditioning, postconditioning, mechanisms, enzyme

\section{Background}

Over the last 30 years, our knowledge of the cardiac effects of various anesthetic drugs employed for patients undergoing heart surgery has helped us understand that the selection of hypnotic drug in the intraoperative and postoperative periods can (in addition to ensuring these patients' sedation) serve as cardioprotective therapy through various mechanisms. In 1986, Murry et al developed the first animal model to reveal a cardioprotective effect through ischemic preconditioning (PreC) with the performance of small episodes of sublethal ischemia, which subsequently decreased the amount of affected myocardium during prolonged interruptions in coronary flow, unlike the situation in those animals in which this maneuver was not performed. ${ }^{1}$ In 2003, Zhao et al reported that brief episodes of ischemia-reperfusion conducted cyclically after a prolonged period of ischemia (but before starting the reperfusion) reduced the damage produced by the reperfusion, thanks to ischemic postconditioning (PostC). 
Since then, numerous studies have been conducted with various drugs, including halogenated gases, to assess the presence of anesthetic PreC and PostC. ${ }^{2-4}$

\section{Effector mechanisms of myocardial damage induced by ischemia and reperfusion}

During cardiac ischemia, an interruption occurs in the energy supply to myocytes. Consequently, at the cellular level, the concentration of lactate and other metabolites increases, intracellular $\mathrm{pH}$ decreases, and there is rapid depletion of the cellular adenosine triphosphate (ATP) reserves. ${ }^{5}$ The mitochondria typically produce ATP within the cardiac cells and during ischemia and have a high oxygen requirement, which entails a high production of reactive oxygen species (ROS). Mitochondria also regulate the intracellular levels of ions, which are essential to preventing processes of cell damage, induced mainly by the increase in calcium ion $\left(\mathrm{Ca}^{2+}\right)$ concentrations. The loss of ATP deposits causes severe ionic disorders in the cells. First, there is a sustained increase in intracellular sodium $\left(\mathrm{Na}^{+}\right)$concentrations, due to the failure of the sodium-potassium $\left(\mathrm{Na}^{+} / \mathrm{K}^{+}\right)$pump, which triggers activation of the $\mathrm{Na}^{+} / \mathrm{Ca}^{2+}$-exchange membrane in the reverse direction, decreasing intracellular $\mathrm{Na}^{+}$concentrations but increasing $\mathrm{Ca}^{2+}$ concentrations. The increase in $\mathrm{Ca}^{2+}$ levels is one of the triggers of cell damage through the impairment of the cell-membrane structure, which culminates in cell death. ${ }^{6}$

In addition to the effects described in ischemia episodes, reperfusion also includes $\mathrm{Ca}^{2+}$ overload, inadequate ATP synthesis, low nitric oxide (NO) production, and oxidative stress by ROS that eventually cause cell damage. ${ }^{7-10}$ When blood flow is restarted, there is a paradoxical increase in ATP concentrations, which (far from beneficial) is directly related to the damage in reperfusion through the hypercontracture of cardiomyocytes, the disruption of its membrane, and ultimately cell death (band necrosis). ${ }^{10,11}$ Coupled with this, the cell attempts to maintain internal homeostasis by eliminating hydrogen $\left(\mathrm{H}^{+}\right)$ions that have accumulated in the cell's interior through an $\mathrm{Na}^{+} / \mathrm{H}^{+}$-exchange mechanism in the plasma membrane, which in turn activates the $\mathrm{Na}^{+} / \mathrm{HCO}_{3}^{-}$cotransporter. Both processes increase intracellular $\mathrm{Na}^{+}$levels, which once again are controlled by an exchange with the external medium of $\mathrm{Na}^{+}$for $\mathrm{Ca}^{2+}$. The mitochondrial synthesis of ATP is reactive and initiates the $\mathrm{Ca}^{2+}$ ATPase of the cells' sarcoplasmic reticulum, which causes the entry of $\mathrm{Ca}^{2+}$ until it is saturated. The massive increase in $\mathrm{Ca}^{2+}$ levels reaches a point at which the cell must expel the $\mathrm{Ca}^{2+}$ back to the cytosol through the ryanodine receptors, participating significantly in cell damage and apoptosis. ${ }^{12,13}$ Lastly, the ion movements cause edema and disintegration of the organelles and cell cytoskeleton through the created osmotic gradient. ${ }^{14-16}$ This pathophysiological mechanism can be extended to neighboring cells through the gap junction, which causes an increase in cell apoptosis. ${ }^{17-20}$

Another mechanism of considerable importance for explaining cell damage by reperfusion is the loss of mitochondrial integrity due to a sudden change in membrane permeability. ${ }^{21,22}$ The main factors that produce this mitochondrial dysfunction are recovery of $\mathrm{pH}$, oxidative stress, and $\mathrm{Ca}^{2+}$ overload, which induce the abrupt opening of MPTPs, which are related to conductance in the internal mitochondria membrane. ${ }^{23-27} \mathrm{~A} \mathrm{pH}$ level $<7.4$ decreases membrane permeability and reduces intracellular $\mathrm{Ca}^{2+}$ levels; however, $\mathrm{pH}$ levels $>7.4$, coupled with high intracellular inorganic phosphorus and ROS levels and low NO levels, produces the opposite effect. ${ }^{28-31}$ Depending on how long the MPTPs remain open, the following processes will occur: induced cardioprotective mechanisms (short duration), entry of high-molecular-weight ions and solutes $(1.5 \mathrm{kDa})$, and swelling of the matrix and loss of critical cellular electrochemical gradients, with the hydrolysis of cellular ATP by ATPase and cell apoptosis (long duration). ${ }^{32-35}$

The combination of the main mechanisms - MPTP dysfunction and the increase in intracellular calcium levels - produces the activation of phospholipase $A_{2}$ and calpain (proteases that require the interaction of calcium for their activation and are inhibited during acidosis). During reperfusion, the sudden normalization of $\mathrm{pH}$ and increase in $\mathrm{Ca}^{2+}$ levels and calpain all collaborate in cell destruction and cause the $\mathrm{Na}^{+} / \mathrm{K}^{+}$ATPase pump to malfunction, which produces an increase in the two cations responsible for cell damage $\left(\mathrm{Na}^{+}\right.$and $\left.\mathrm{Ca}^{2+}\right) \cdot{ }^{36-40}$

Mitochondrial damage with the release of the protein $\mathrm{Bcl} 2$, the effect of the platelet L-selectin, and the dysfunction of $\mathrm{Ca}^{2+}$ homeostasis, neutrophils, and fibroblasts can contribute to damage by reperfusion and ultimately to cell death. ${ }^{41-45}$ Another enzyme group, known generically as MAPKs, has a decisive role in intracellular signaling processes within inflammatory processes and in the regulation of proliferation, differentiation, and apoptosis. MAPKs also regulate the activation of caspases, mainly 3,6 and 9, which ultimately cause cell death. ${ }^{44,45}$ 


\section{Ischemic PreC and anesthetic}

In 1986, Murry et al found (in an animal model) that short episodes of ischemia, instead of worsening the myocardial lesion when an infarction was ultimately induced, reduced the size of the lesion, thanks to a protective ischemic PreC effect. Through endogenous adaptation mechanisms, the limited ischemic episodes protected against larger ischemia, with less ventricular dysfunction and incidence of arrhythmias. ${ }^{1}$ From the clinical point of view, the possibility of inducing pharmacological PreC should help us achieve the same benefits as with ischemic stimulus, but without the risk represented by transient exposure to an interruption in coronary flow in the myocardium. ${ }^{46}$

Various drugs have been studied to determine whether they have PreC properties for the heart, including (at the anesthetic level) halogenated hypnotics. ${ }^{3,4}$ The cardioprotective effects of volatile anesthetics were discovered before the concept of ischemic PreC was defined by Murry et al. ${ }^{1}$ In 1976, Bland and Lowenstein observed that after clamping the coronary artery of dogs for a short period, halothane reduced ST-segment abnormalities in electrocardiography. ${ }^{47}$ Years later, Warltier et al showed that pretreatment with halothane or isoflurane improved the systolic function of the left ventricle when an ischemic episode occurred. ${ }^{48}$ Cason et al subsequently showed that exposure to isoflurane triggered an effect similar to that of ischemic PreC, through cardioprotective mechanisms. ${ }^{49}$

\section{Phases}

Within ischemic PreC, we can highlight two phases (based on when they occur) with different durations: early and late PreC. Early PreC occurs a few minutes before the ischemic stimulus, and protects the myocardium for 1-2 hours with considerable intensity. Late PreC occurs 24 hours after the initial triggering stimulus, without the need for the stimulus to be repeated, and this phase induces lower but longer-lasting protection ( $\sim 72$ hours). ${ }^{50-53}$

Anesthetic PreC behaves in a similar manner to ischemic PreC, sharing phases and mechanisms of action. Early anesthetic PreC is based on the drug effect of the halogenated gases in the ATP-sensitive $\mathrm{K}^{+}$channels, preserving the $\mathrm{PKC}$ and adenosine receptors, in the same manner as ischemic PreC. Late or "second window" PreC is related to the synthesis of cardioprotective mediator proteins, and lasts 24-72 hours after their administration. ${ }^{54,55}$ In 2013, Qiao et al reported the fundamental mechanisms of late anesthetic (or second window) PreC in rat hearts. These mechanisms include activation of $\mathrm{NF} \kappa \mathrm{B}$, the regulation of autophagy and the attenuation of the expression of $\mathrm{TNF} \alpha$, IL- $1 \beta$, and caspase $3 .^{56}$

\section{Mechanisms of PreC}

The cellular and molecular mechanisms involved in the anesthetic PreC of the heart have been the focus of numerous studies over the last 15 years. ${ }^{57-59}$ In general, both ischemic and anesthetic PreC in the heart have cellular mechanisms of action with common pathways. However, the genetic expression profiles in anesthetic PreC have differences from ischemic profiles. ${ }^{60}$ Numerous studies have attempted to describe the effector mechanisms of cardioprotection with halogenated gases, identifying the pathways and enzymes involved in the mechanisms..$^{55,58,59}$

According to Zaugg et al, when there is a stimulus with the capacity to trigger the cell-PreC mechanism, all mediators are activated, from the cell-membrane receptor (initial location of the action) to the final effector. ${ }^{57,58}$ Nitric oxide synthase (NOS) triggers the release and formation of $\mathrm{NO}$ through a PreC stimulus. This increased production of NO and the activation of $\mathrm{PKC}$ in the myocardium during brief periods of ischemia and reperfusion are associated with cardioprotective effects.

In both early and late anesthetic PreC, participation is required of various myocardial fiber-surface receptors: adenosine $\left(\mathrm{A}_{1}, \mathrm{~A}_{3}\right)$, purine $\left(\mathrm{P}_{2 \mathrm{Y}}\right)$, endothelin $\left(\mathrm{ET}_{1}\right)$, acetylcholine $\left(\mathrm{M}_{2}\right), \alpha_{1}$ - and $\beta$-adrenergic, angiotensin II (ATII), bradykinin $\left(\mathrm{B}_{2}\right)$, and opioid $\left(\delta_{1}\right.$ and $\left.\mathrm{k}\right)$ receptors. ${ }^{58}$ Hanouz et al analyzed through in vitro studies how PreC with halogenated gases in myocardial tissue is produced through the activation of adenosine $A_{1}(\alpha$ and $\beta$ ) receptors and mitochondrial ATP-sensitive $\mathrm{K}^{+}$channels. ${ }^{61}$ These receptors will produce a $\mathrm{G}$ protein-mediated intracellular signal, and are the secondmost important messengers among the signaling pathways. The receptors transmit the stimulus to the phospholipases $\mathrm{C}$ and $\mathrm{D}$, starting the synthesis of inositol triphosphate $\left(\mathrm{IP}_{3}\right)$ and diacylglycerol, which activate the release of $\mathrm{Ca}^{2+}$ from the reticulum and to the various isoforms of PKC. ${ }^{62}$

$\mathrm{PKC}$ is activated by $\mathrm{G}$ proteins, phospholipids, diacylglycerol, $\mathrm{Ca}^{2+}, \mathrm{ROS}$, and $\mathrm{NO}$, and generates a signal that is transmitted to the effectors, the ATP-sensitive $\mathrm{K}^{+}$channels of the mitochondria, and sarcoplasm. PKC activation is considered essential by numerous authors, because it is the common mediator of numerous pathways involved in cardioprotection. ${ }^{63}$ The cascade continues with the activation of other intermediaries, such as tyrosine 
kinase and PKC. These coupled systems in turn stimulate the MAPKs. Once activated, the MAPKs translocate the cell nucleus to activate specific genes, which results from the action on intracellular effectors or membrane effectors, such as ATP-sensitive $\mathrm{K}^{+}$channels (early PreC) or in the synthesis of the cytoprotective protein (late PreC) to trigger cardioprotection against ischemic damage. ${ }^{64,65}$ There are differences between the role of MAPKs in the transduction of signals in ischemic and anesthetic PreC. MAPKs (ERK1/2 and p38) can act as triggers and as mediators in ischemic PreC. In anesthetic PreC, however, MAPKs seem to have mediator effects. ${ }^{64,65}$

The benefit of using halogenated gases in an ischemiareperfusion lesion has been described in an anesthetic PreC model. The halogenated gases attenuate both the NFאB activation and the expression of its genes, which are inflammation regulators during reperfusion. The use of sevoflurane has been shown to cause NK cells to act as a trigger and mediator by regulating the apoptotic protein $\mathrm{Bcl} 2$ during the PreC period and the inflammatory proteins ICAM1 and TNF $\alpha$ during the reperfusion period. ${ }^{66}$ In 2013, Qiao et al described the fundamental mechanisms of late anesthetic (or second window) PreC in rat hearts. These mechanisms include the activation of $\mathrm{NF} \kappa \mathrm{B}$, the regulation of autophagy, and the attenuation of the expression of TNF $\alpha$, IL-1 $\beta$, and caspase 3.56

There is ample evidence that the interaction between the mitochondria and ROS acts as a trigger for myocardial protection. At the start of reperfusion, a burst of ROS is generated, which contributes to myocardial depression through disorders in intracellular homeostasis and damage to the cell membrane, among others; however, small quantities can have beneficial effects during ischemia. Low ROS levels are generated during PreC with halogenated gases, probably through the direct or indirect interaction of the anesthetic agent with complex I and/or III of the electron-transport chain. ${ }^{66,67}$ It has been reported that the stimulation of the ATP-sensitive $\mathrm{K}^{+}$channels increases the formation of ROS, which activate more PKs. Free radicals can also serve as triggers for inducing the opening of mitochondrial ATP-sensitive $\mathrm{K}^{+}$channels, which subsequently create additional ROS required for PreC. ${ }^{68} \mathrm{AMPK}$ mediates PreC in cardiac cells by regulating the activity and recruitment of sarcolemmal $\mathrm{K}_{\mathrm{ATP}}$ channels without being part of the signaling pathway that regulates mitochondrial membrane potential in cells with ATP depletion and increased adenosine monophosphate (AMP):ATP ratio. ${ }^{69}$

Finally, the PDK1-signaling pathway mediates PreC too, which could be mediated by activation of the mitochondrial
$\mathrm{K}_{\text {ATP }}$ channel. ${ }^{70}$ Extensive evidence from experimental studies has shown that volatile anesthetics protect the heart from ischemic myocardial injury in animal models, and that they also have the potential to provide renal and cerebral protection. In addition to an immediate window of protection 1-2 hours after the PreC stimulus, a delayed phase of protection from PreC that persists for 2-3 days has been described as late PreC. ${ }^{7}$ Experimental evidence supports several hypotheses of molecular interactions by volatile anesthetics resulting in potential myocardial protection.

\section{Clinical evidence of anesthetic PreC}

According to Warltier et al, anesthetic PreC with desflurane, isoflurane, or sevoflurane reduces the size of the infarction to the same degree as ischemic PreC. ${ }^{48}$ The administration of any volatile anesthetic in the isolated hearts of rats, guinea pigs, or rabbits for 2-10 minutes has been shown to induce PreC, with a reduction in infarction size and improvement in postischemic cardiac dysfunction; in other words, less "myocardial stunning". 65,71

The administration of a volatile anesthetic before myocardial ischemia has been shown to have a PreC effect, even in clinical practice. ${ }^{3,4}$ All of the studies have focused on assessing myocardial damage through troponin I levels, and their results show that the use of halogenated hypnotics results in less myocardial damage and better myocardial function. ${ }^{3,4}$ The consequences of this protective effect are shorter stays in critical care units and reduced morbidity and mortality. ${ }^{71}$

In 2002, De Hert et al conducted a study that compared the use of intraoperative sevoflurane with that of propofol. The results revealed better postoperative ventricular function in the group with sevoflurane and release of fewer troponins. These results were later confirmed in patients with high perioperative risk (elderly patients and those with poor ventricular function). ${ }^{72,73}$ In subsequent studies, De Hert et al examined various anesthetic regimens according to the duration and exposure to sevoflurane. ${ }^{74}$ The administration of sevoflurane throughout the procedure had a significant effect on reducing troponin I concentrations and hospital stays. De Hert et al also conducted a randomized multicenter trial with 414 patients who underwent cardiac surgery. Their intent was to study the benefit of using volatile anesthetics versus propofol in reducing myocardial damage, mortality, and hospital stays. Despite observing no significant differences in postoperative troponin I levels, they observed a favorable tendency with the use of halogenated anesthetics compared with propofol. Mortality 
at 1 year was $12.3 \%$ in the propofol group versus $3.3 \%$ in the sevoflurane group and $6.7 \%$ in the desflurane group. Hospital stays were also shorter in the groups treated with volatile anesthetics. ${ }^{75}$

The cardioprotective effect of volatile anesthetics compared with propofol in patients who undergo heart surgery was confirmed in later studies. ${ }^{76,77}$ Tritapepe et al showed that the continuous administration of desflurane at a minimum alveolar concentration during aortocoronary bypass surgery decreased myocardial damage, with lower troponin I levels when compared with the infusion of propofol. ${ }^{77}$

In a meta-analysis that included 1,922 patients who underwent heart surgery, Landoni et al found significant reductions in morbidity and mortality in the group with volatile anesthetics (sevoflurane and desflurane) compared with an intravenous hypnotic group..$^{71}$ A recently published meta-analysis, the objective of which was to assess the difference between the use of volatile anesthetics and the use of propofol during surgery, in the total of 3,642 patients who underwent heart surgery found twice the mortality in the intravenous hypnotic group. ${ }^{78}$

Ballester et al assessed oxidative stress levels during heart surgery without cardiopulmonary bypass (CPB) through the analysis of peroxidation of lipids and stress biomarkers. These levels remained constant in the sevoflurane group, but increased significantly in the control group, who were treated with propofol. ${ }^{79}$

However, in contrast to De Hert et al, ${ }^{75}$ anterograde or retrograde cold-blood cardioplegia has been used to immobilize the myocardium during grafting, thus excluding an additional protective effect by cross-clamp defibrillation. In contrast to the evidence presented up to now, there have been a number of trials showing that volatile anesthetic agents in cardiac surgery do not reduce postoperative troponin levels. Xia et al performed a study with 54 patients in which high doses of propofol $(120 \mu \mathrm{g} / \mathrm{kg} / \mathrm{min})$, low doses of propofol ( $60 \mu \mathrm{g} / \mathrm{kg} / \mathrm{min})$, or isoflurane was administered during the pump. The results were lower troponin I levels, a better cardiac index, and fewer requirements for inotropic agents in the first group compared with the other two groups. One explanation for this finding could be the aortic clamping times for all groups, which exceeded 80 minutes. ${ }^{80}$ Similarly, Piriou et $\mathrm{al}^{81}$ showed that the administration of sevoflurane at a minimum alveolar concentration for 15 minutes before CPB did not produce better results than the use of propofol in reducing markers of myocardial damage. Possible causes for this trial's negative results included the dose, which could have been too low, the administration pattern, which was not intermittent, the administration time, which may have been too short (and/or washout period too long), and/or too long a lavage period. ${ }^{81}$

The phenomenon of anesthetic conditioning with halogenated gases has produced promising lines of research and shown continuous progress in recent years. A better understanding of the basic science to understand the gases' mechanisms of action could provide anesthesiologists with strategies to reduce the incidence of perioperative cardiac ischemia and/or reperfusion lesions.

\section{Ischemic and anesthetic PostC Reperfusion lesion: mitochondria as "origin" of cell death}

Episodes of myocardial ischemia frequently occur during heart surgery, with or without $\mathrm{CPB}$, and in coronary percutaneous procedures. Heart surgery with $\mathrm{CPB}$ is associated with overall prolonged and induced ischemia of the heart, with the intention of protecting the heart during surgery. Reperfusion, a procedure performed when finishing the surgical process, is necessary to recover the ischemic myocardium, induced during the $\mathrm{CPB}$, and produced by the opening of the native vessels or through coronary grafts during surgical or percutaneous revascularization of patients with ischemic heart disease. ${ }^{82,83}$ In terms of restarting blood flow in coronary circulation, the phenomenon of cell lesion during ischemiareperfusion has been described. ${ }^{84-86}$

\section{Mechanism of cell lesions by reperfusion}

The molecular basis of ischemia-reperfusion damage is the halting of oxidative phosphorylation, which limits the production of ATP and increases intracellular lactic acid. Coupled with the increase in $\mathrm{CO}_{2}$ in the extracellular space and an inability to eliminate it, due to the interruption in the flow, cellular acidosis is produced, which within a few minutes can reach $\mathrm{pH}$ values of approximately $6.4 .{ }^{87}$ Restoring the flow restarts cellular respiration, resulting in the restoration of the mitochondrial membrane potential and ATP synthesis. ${ }^{1}$

Mitochondria play an essential role in both life and death of the cell. During reperfusion, the calcium overload, massive production of free ROS, by the mitochondria and destruction of the capacity of cellular oxidative phosphorylation induce the opening of MPTPs. ${ }^{88,89}$ During ischemia, the reduction in ATP concentrations and increase in phosphate concentrations sensitize the mitochondria to the opening of MPTPs, which is usually compensated by the reduction in intracellular $\mathrm{pH}$, which prevents its opening. 
The opening of MPTPs causes mitochondria depolarization, edema, and rupture of the external membrane, irreversibly altering its function, and causes the mitochondria to provide ATP and maintain cardiac functionality, directing the cells toward apoptosis, resulting in myocardial necrosis when the damage is severe. ${ }^{34}$ Restoring the flow produces the phenomenon of massive ROS production by the mitochondria, which exceeds the cellular antioxidant capacity, causing cell damage by oxidative stress, with an increase in the production of superoxide anions and the accumulation of neutrophils in the ischemic area ${ }^{90-92}$ The final mechanism by which MPTP malfunctions in reperfusion appears to be related to the binding of adenine nucleotide-translocator ligands to $\mathrm{CypD}$ to the MPTP subunit and its increase in sensitivity to $\mathrm{Ca}^{2+}{ }^{23}$

\section{Ischemic PostC}

PostC is defined as small episodes of ischemia-reperfusion at the start of the reperfusion process. PostC decreases the damage caused when restarting the cellular blood flow, due to the slowing and progression of the flushing of the metabolites produced during the ischemia and the process of intracellular $\mathrm{pH}$ normalization, thus preventing or reducing the lesions resulting from this process. ${ }^{82}$ PostC is related to significant reductions in infarction size in both experimental animal models and humans. ${ }^{86}$ In 2003, Zhao et $\mathrm{al}^{2}$ introduced the concept of PostC in a study conducted on dogs. The animals were divided into three groups. The first was the PreC group, in which the left anterior descending (LAD) artery was occluded for 5 minutes. Reperfusion was then applied for 10 minutes. Lastly, the LAD artery was clamped for 60 minutes. In the second group (PostC), LAD-artery occlusion was performed for 60 minutes, after which (at the start of reperfusion) three cycles of ischemia-reperfusion, each lasting 30 seconds, were performed. The third group was the control group, in which only the ischemic event was performed, using the same duration as in the other two groups. The infarction area was analyzed in each group, and was found to be similar in the PreC and PostC groups, with significant differences compared with the control group. Zhao et al concluded that PostC is at least as effective as PreC in reducing the ischemic area, and proposed the need for further studies to evaluate this mechanism of myocardial protection in different types of surgeries where it could be important. ${ }^{2}$ The mechanisms by which this benefit is produced were initially related to the reduction in the release of free radicals and inflammation mediators and of mitochondrial calcium, as well as to an improvement in endothelial function. It was subsequently observed that the effector mechanism of PostC is related to the activation of enzyme pathways that are known to be part of the pathways involved in PreC. ${ }^{93}$

Luo et al conducted a protocol for studying the effects of PostC in a pediatric population undergoing corrective surgery for tetralogy of Fallot, performing 30-second aortic clamping and declamping before reperfusion. The result was a significant reduction in troponin I and CK-MB levels in this patient group. ${ }^{94}$ Another study conducted to assess these maneuvers in adult patients undergoing aortic valvereplacement surgery confirmed their benefit. ${ }^{95}$ However, the aortic clamping and declamping maneuvers are not safe, and are associated with a high risk of thromboembolic complications. ${ }^{96,97}$ As with ischemic PreC, the possibility of maintaining the benefit of PostC with the use of anesthetic drugs, which avoid the risks of these maneuvers, has been the object of study. ${ }^{94}$ Additionally, patients who undergo heart surgery could benefit from exposure to halogenated gases in the immediate postoperative period after their arrival in the intensive care unit (ICU), thanks to late PostC. ${ }^{98}$

\section{Pharmacological PostC: cardioprotection with halogenated anesthetics}

Halogenated gases have nonanesthetic properties that favor the endogenous adaptive response of the myocardium to ischemic events. ${ }^{53}$ This effect is independent of the gases' hypnotic properties. PostC induced by these drugs is a phenomenon by which exposure of the myocardium to these agents at the start of reperfusion after prolonged ischemia reduces the myocardial lesion. ${ }^{89}$

\section{Cell mechanisms of PostC}

PreC and PostC induced by halogenated gases share intracellular effector mediators and pathways whose ultimate objective is to prevent the accumulation of intracellular $\mathrm{Ca}^{2+}$ and thereby prevent injury by ischemia-reperfusion. ${ }^{99}$ The molecular mechanisms that lead to PostC can be separated into triggers, intracellular pathways, and common final effectors. ${ }^{96}$

\section{Triggers and $\mathrm{G}$ proteins: start of the PostC cascade}

The activation of adenosine, bradykinin, and opioid receptors is a determinant of the start of PostC cardioprotection. These receptors are coupled with G proteins, and their stimulus generates an intracellular cascade through second messengers, which ultimately leads to cell protection through an end effector. ${ }^{89}$ The intracellular pathways of the second messengers involved are the reperfusion injurysalvage kinase (RISK) pathway and the survivor-activating factor-enhancement (SAFE) pathway, and the end effector 
in which both converge is the mitochondria (mitochondrial permeability transition pore [MPTP]). ${ }^{91}$ The blocking of these receptors, either through the use of $\beta$-blockers or bradykinin and adenosine antagonists, has been shown to inhibit the start of desflurane-mediated PostC. ${ }^{99,100}$

Lemoine et al compared desflurane-induced PostC in atrial tissue in a diabetic and a nondiabetic population by administering increasing concentrations of desflurane. The beneficial response of the drug was reduced in part by changes in the adrenergic receptor of the diabetic population. ${ }^{101}$ Additionally, in desflurane-induced PostC, PKC plays a fundamental role in both myocardial PreC and PostC, because $\mathrm{PKC}$ activates numerous pathways, including the $\mathrm{K}^{+}{ }_{\text {ATP }}$ channels. There is evidence that $\mathrm{PKC}$ is a mediator of the mechanisms activated by this drug, because its block causes the disappearance of desflurane-induced PostC. ${ }^{100}$

\section{RISK pathway}

Myocardial cell apoptosis is increased during the reperfusion period. Hausenloy and Yellon coined the term "RISK pathway" to refer to the antiapoptotic pathways linked to caspases, whose drug activation during the early phases of reperfusion limit the lesion induced by blood-flow resumption. ${ }^{102}$ This enzyme pathway is formed by the IP3 3-kinase/IP(3)K, Akt, MEK and ERK 1/2 cascades.

PostC induces desflurane and sevoflurane activates (through the stimulation of the $\mathrm{IP}_{3} \mathrm{~K}-\mathrm{Akt}$ and MEK-ERK1/2 pathways) the Akt, ERK1/2, p70s6K (70 kDa), and NOS proteins. The $\mathrm{p} 70 \mathrm{~s} 6 \mathrm{~K}$ protein inhibits the activation of GSK $3 \beta$. NO (produced by NOS), and GSK3 $\beta$ inhibits the opening of the MPTP. ${ }^{89}$ NO has a double-cardioprotective effect, due to its direct effects of vasodilation and anti-inflammation and its indirect effects of inhibiting GSK3 $\beta$ and opening $\mathrm{K}_{\text {ATP }}$ channels, which stabilizes the mitochondrial membrane, decreasing cellular $\mathrm{Ca}^{2+}$ overload and inhibiting the opening of the MPTP. ${ }^{103}$

Moreover, PostC induced by desflurane and sevoflurane has antiapoptotic effects, due to the preservation of mitochondrial integrity through the inhibition of the opening of the MPTP. ${ }^{89}$ The activation of PI3K/Akt and ERK1/2 regulates expression of SUR2A, which seems to be a crucial cardioprotective protein. ${ }^{104}$

\section{SAFE pathway}

The SAFE pathway has been identified as an enzyme pathway responsible for PreC and PostC, and is independent of the RISK pathway. This cascade includes the activation of TNF $\alpha$ and STAT3. TNF $\alpha$ activated during reperfusion seems to have conflicting effects, depending on its concentration.
At high concentrations and through its binding with $\mathrm{TNF} \alpha \mathrm{R}_{1}$, apoptosis and myocardial dysfunction are favored, while low concentrations in the initial phases of reperfusion and binding to $\mathrm{TNF} \alpha \mathrm{R}_{2}$ form a fundamental pathway of cardioprotection, which also limits the production of TNF $\alpha$ and its adverse effect, in latter phases. There are several experimental animal studies that have shown that the PostC effect of sevoflurane is eliminated in the diabetic population, both by inhibition of PI3K and the STAT3 pathway. ${ }^{105-107}$

\section{Clinical studies}

The administration of halogenated drugs before and after the ischemic episode produces a greater clinical benefit in patients who undergo myocardial revascularization surgery, with a reduction in myocardial damage and length of stay in the ICU and hospital. ${ }^{7}$ Numerous studies have shown the cardioprotective effect of desflurane and sevoflurane through their PreC and PostC mechanisms during heart surgery. ${ }^{74,77,108-110}$ There are, however, very few studies that have attempted to determine the impact of each of them through different administration protocols for halogenated gases during and after surgery in this patient group. ${ }^{98,111-114}$

Our group conducted a pilot study with 40 patients that assessed the effect of sevoflurane versus propofol in coronary bypass surgery without extracorporeal circulation. Exposure to these drugs was extended during the first 6 postoperative hours. The patients were randomized to two groups according to the agent used as a hypnotic during and after surgery. We compared hemodynamic parameters (cardiac index, mixed venous oxygen saturation, mean pulmonary arterial pressure, mean blood pressure, and central venous pressure) and biochemical markers (CRP, troponin I, and N-terminal brain natriuretic peptide prohormone [NT-proBNP]) in both groups. Results showed significant differences in troponin I and NT-proBNP levels. Postoperative sedation with sevoflurane prolonged the beneficial effects of PreC with intraoperative halogenated gases. ${ }^{111}$ This study served to develop a clinical trial to clarify the weight of late PostC versus intraoperative PreC and PostC. To this end, we collected equal hemodynamic and laboratory parameters in three patient groups (20 patients per group), according to the hypnotic administered during surgery and after surgery for sedation until extubation (group SS, sevoflurane administered both during and after surgery; group PP, propofol administered both during and after surgery; group SP, sevoflurane administered during surgery and propofol administered for sedation after surgery). NT-proBNP and troponin I concentrations were smaller in group SS when compared with the 
other two groups, and the requirements for inotropic agents were also less than for this group. There were also significant differences between groups SP and PP favoring the former. The conclusion of this study was that the administration of sevoflurane during and immediately after surgery was the therapeutic regimen with the greatest benefit for this patient group, probably due to late PostC. ${ }^{112}$

Steurer et al compared the effects of sedation with sevoflurane $(n=46)$ versus propofol $(n=56)$ in the postoperative period of heart surgery, administering propofol as a hypnotic in the intraoperative period. The main objective of the study was to assess whether there were significant differences in myocardial damage between the groups 24 hours after surgery by measuring plasma concentrations of troponin $\mathrm{T}$, $\mathrm{CK}-\mathrm{MB}$, and $\mathrm{CK}$. The results showed that troponin $\mathrm{T}$ levels were lower in the sevoflurane group, although there were no differences in length of stay in the ICU or hospital between the two groups. Steurer et al confirmed that postoperative sevoflurane is a cardioprotector and can be a therapeutic tool in preventing and treating ischemia and postoperative myocardial dysfunction. ${ }^{98}$

Soro et $\mathrm{al}^{113}$ investigated the effects of two sedation protocols with propofol and sevoflurane on a total of 75 patients. In each of the groups, the drug chosen for postoperative sedation was maintained during surgery, although during the $\mathrm{CPB}$ the same drug was employed in both groups. There were no differences in the degree of myocardial lesion or in length of stay in the ICU or hospital. For Soro et al, maintenance of sedation with sevoflurane during surgery produced no cardioprotective effects compared with propofol. ${ }^{113}$ In our opinion, one of the methodological problems of this study was that it did not consider the influence of the use of each of the drugs evaluated in the CPB. De Hert et $\mathrm{al}^{75}$ showed that there were significant variations with the intraoperative use of sevoflurane compared with propofol only when administered continuously (including CPB), which was not performed in the study by Soro et al. ${ }^{113}$

Hellström et al compared two groups (each with 50 patients) in which postoperative sedation was performed with propofol or sevoflurane. Intraoperative anesthesia maintenance was performed with sevoflurane, except for the CBP period and transfer to the ICU, where propofol was used. After arriving in the ICU, the patient was kept sedated for 2 hours. The study's main end point was troponin $\mathrm{T}$ as a marker of myocardial lesion. There were no significant differences in terms of troponin $\mathrm{T}$ levels between the two groups, although initial troponin $\mathrm{T}$ levels were higher in the sevoflurane group. ${ }^{114}$ As with the Soro et al ${ }^{113}$ study, the administration of propofol in CPB and the interruption in the administration of sevoflurane for transfer to the ICU could have been the cause of the results, as well as the shorter postoperative sedation time than in studies in which there were differences between the groups.

\section{Conclusion}

The use of halogenated drugs during and after heart surgery, when compared with intravenous drugs, has been shown to decrease perioperative myocardial damage. ${ }^{71-75,111,112}$ The mechanism by which this effect is produced is directly related to drug PreC and PostC. ${ }^{59,62,89}$ The pathways involved in both types of conditioning have numerous points in common. ${ }^{115}$ The bases that advance our understanding of anesthetic PreC and PostC were developed in the study of these protective mechanisms, triggered by ischemia and organ reperfusion. ${ }^{50-52,82-86}$

In anesthetic PreC and PostC and once the halogenated hypnotic is administered, the membrane receptors are activated due to the release of various agonist mediators of this action, starting the enzyme cascade that triggers the mechanisms of myocardial protection. ${ }^{57-60,89,91}$ The enzymes of the RISK and SAFE groups are largely responsible for this action, due to the activity of the various kinases that compose them. PKG and NO play a complementary role by acting as activators. . $2,64,65,91,103^{-10}$ The final objective of cardioprotection is focused on maintaining intracellular homeostasis through the preservation of the fundamental cell organelle in the production of this effect - the mitochondria - and its normal function..$^{68,69,103}$

The beneficial effect on symptoms appears to be related to the greater duration of exposure to the drug. ${ }^{72-75}$ Initial studies showed that maintaining the halogenated anesthetic throughout the operation was the best strategy for producing cardioprotection, which translates into a lower use of inotropic drugs and shorter stays in the ICU and hospital. ${ }^{74,110}$ Several studies subsequently evaluated the possibility that these benefits were extended with the use of sevoflurane as a hypnotic for the postoperative sedation, with varying results. ${ }^{98,112-114}$ These studies based their hypotheses and results on the basis of early and late PreC and anesthetic PostC. However, our understanding of these mechanisms was developed in the basic sciences, because none of the studies mentioned determined whether the enzymes described as mediators of anesthetic PreC and PostC were responsible for the results or the measure in which each of them act.

In our opinion, it is very difficult to separate the two mechanisms and determine which is fundamentally responsible for the cardiac benefit in studies conducted in hospital. We must 
thus assume that both mechanisms are responsible for the cardioprotection. The major benefit related to its maintenance in the postoperative period further complicates the possibility of attributing a specific percentage weight of this effect to each of them. ${ }^{111,112}$ The term "myocardial conditioning" encapsulates both effects, and solves the conceptual problem in this type of study.

However, the fundamental problem is not resolved by coining a term that encompasses both effects. Understanding the weight of each of the various enzymes described as part of myocardial conditioning, in terms of the benefit of administering inhaled hypnotics compared with intravenous agents, would help us advance in the development of numerous strategies in the future, thus achieving various strategies for stimulating the fundamental pieces of this therapeutic mechanism.

The various studies conducted on heart surgery have mainly assessed the concentration of troponin $\mathrm{I}$ or $\mathrm{T}$ as a marker of myocardial damage as the primary end point. ${ }^{72-75,98,111,114}$ Troponin levels roughly represent the degree of cellular apoptosis. Their increase is related to postoperative myocardial injury in conditions in which cardiac cell death is produced by numerous mechanisms and in which their increase is the result of the failure or success of the mechanisms described in this review. ${ }^{116,117}$ However, in patients with a high risk of perioperative ischemic events, there could be an induced benefit for the heart that is not assessable with troponin T or I levels, due to the ultimate lack of myocardial damage. This approach does not rule out the presence of myocardial conditioning, which could be demonstrated if we truly understood the behavior of the main enzymes related to the benefit of exposure to halogenated agents in this type of patient. According to our last study (Guerrero-Orriach et al, unpublished data, 2016), these enzymes differ from those evidenced in animal models.

In our opinion, there should be cardioprotection even if there is no myocardial damage, because halogenated drugs have the capacity to lead to cardioprotection without relating their effect to the ischemia or reperfusion, but rather to exposure to the drug (drug cardiac conditioning), with the possibility that there is protective cell adaptation independent of the presence of myocardial damage..$^{53,65-71,89}$ In conclusion, our line of research progresses toward the determination of whether cardioprotection truly exists, regardless of the production of myocardial damage. In our opinion, cardioprotection and myocardial damage are independent events, although clinically representative when there is ultimately a lesion or myocardial damage.
Our research group, through its three recent studies conducted with patients who underwent myocardial revascularization surgery without $\mathrm{CPB}$, has compared the use of sevoflurane versus propofol in the intraoperative and postoperative period. The results confirmed that the use of sevoflurane extended to the postoperative period resulted in a lower increase in troponin I levels than the administration of only intraoperative sevoflurane or the administration of propofol in the intraoperative and postoperative periods. These results are directly related to a lower need for inotropic agents and shorter stays in the ICU. ${ }^{111,112}$ In our first two studies, the main objective was to confirm that the effects of early and late PreC and PostC increased as the time of exposure to the drug increased in the first 6 postoperative hours, with the use of sevoflurane becoming part of the perioperative therapy in the treatment and prevention of myocardial damage, regardless of its hypnotic properties.

However, in our last clinical trial (Eudra code 2013001304-11), which was recently completed and is awaiting publication, our hypothesis was that the degree of cardioprotection is dependent on the time of exposure to sevoflurane and that it is based on enzyme differences within the pathways of anesthetic PreC and PostC. We performed this study to understand which enzymes produced this effect and the differences that explain the benefit with the greater exposure to sevoflurane. The selected patients and the surgery performed were the same as those of our previous studies, and the objectives were the following: to confirm the previous results from our other studies (less myocardial damage with greater exposure to halogenated hypnotics) and to determine the mechanisms (enzymes) that produced anesthetic PreC and PostC in the myocardium. The design was based on randomizing the patients into three groups according to the anesthetic regimen (in the first group, we employed intraoperative and postoperative sevoflurane; in the second group, we administered intraoperative sevoflurane and postoperative propofol; and in the third group, the chosen combination was intraoperative and postoperative propofol). With this study, we attempted to shed light on the results of previous studies and determine whether maintaining sevoflurane after surgery truly produced some variation in the proteins responsible for myocardial conditioning compared with the isolated intraoperative use of the halogenated drug. We also attempted to reveal the basis for the benefit of using intraoperative sevoflurane compared with the use of propofol, reported in numerous studies but without the understanding of the behavior of its effector mechanisms. ${ }^{72-75,110}$ Questions with regard to whether halogenated agents without anesthetic 
property have similar protective effect or if agents offering mitochondrial protection could have the same effects as halogenated agents should be studied in the future.

\section{Summary}

A better understanding of the mechanisms related to myocardial conditioning produced by halogenated hypnotics is needed. Clinical studies that reveal the behavior of the various pathways and enzymes related to this effect in patients who undergo heart surgery can help us better understand the cardioprotective effects of halogenated hypnotics and the development of new anesthetic therapies and strategies, which are based on stimulating or inhibiting the key parts of cardioprotection or cell damage.

\section{Acknowledgments}

The authors would like to thank the Foundation for Progress and Health (Fundación Progreso y Salud, Andalusia, Spain), the Andalusian Extremadura Association of Anaesthesiology and Resuscitation (Asociación Andaluza-Extremeña de Anestesiología y Reanimación, Andalusia, Spain), and the Department of Anesthesia, Virgen de la Victoria University Hospital, Malaga, Spain.

\section{Disclosure}

The authors report no conflicts of interest in this work.

\section{References}

1. Murry CE, Jennings RB, Reimer KA. Preconditioning with ischemia: a delay of lethal cell injury in ischemic myocardium. Circulation. 1986; 74:1124-1136.

2. Zhao ZQ, Corvera JS, Halkos ME, et al. Inhibition of myocardial injury by ischemic postconditioning during reperfusion: comparison with ischemic preconditioning. Am J Physiol Heart Circ Physiol. 2003; 285:H579-H588.

3. Belhomme D, Peynet J, Louzy M, Launay JM, Kitakaze M, Menasché P. Evidence for preconditioning by isoflurane in coronary artery bypass graft surgery. Circulation. 1999;100:II340-II344.

4. Julier K, da Silva R, Garcia C, et al. Preconditioning by sevoflurane decreases biochemical markers for myocardial and renal dysfunction in coronary artery bypass graft surgery: a double-blinded, placebocontrolled, multicenter study. Anesthesiology. 2003;98:1315-1327.

5. Reimer KA, Jennings RB. Total ischemia in dog hearts, in vitro - II: high energy phosphate depletion and associated defects in energy metabolism, cell volume regulation and sarcolemmal integrity. Circ Res. 1981;49: 901-911.

6. Perrelli MG, Pagliaro P, Penna C. Ischemia/reperfusion injury and cardioprotective mechanisms: role of mitochondria and reactive oxygen species. World J Cardiol. 2011;3:186-200.

7. Crompton M. The mitochondrial permeability transition pore and its role in cell death. Biochem J. 1999;341:233-249.

8. Kutala VK, Khan M, Angelos MG, Kuppusamy P. Role of oxygen in postischemic myocardial injury. Antioxid Redox Signal. 2007;9: 1193-1206.

9. Ladilov Y, Efe O, Schäfer C, et al. Reoxygenation-induced rigor-type contracture. J Mol Cell Cardiol. 2003;35:1481-1490.
10. Piper HM, Abdallah Y, Schäfer C. The first minutes of reperfusion: a window of opportunity for cardioprotection. Cardiovasc Res. 2004;61: 365-371.

11. Piper HM, Kasseckert S, Abdallah Y. The sarcoplasmic reticulum as the primary target of reperfusion protection. Cardiovasc Res. 2006;70: $170-173$.

12. Inserte J, García-Dorado D, Ruiz-Meana M, et al. Effect of inhibition of $\mathrm{Na}^{+} / \mathrm{Ca}^{2+}$ exchanger at the time of myocardial reperfusion on hypercontracture and cell death. Cardiovasc Res. 2002;55:739-748.

13. Abdallah Y, Gkatzoflia A, Pieper H, et al. Mechanism of cGMP-mediated protection in a cellular model of myocardial reperfusion injury. Cardiovasc Res. 2005;66:123-131.

14. García-Dorado D, Théroux P, Munoz R, et al. Favorable effects of hyperosmotic reperfusion on myocardial edema and infarct size. $\mathrm{Am} J$ Physiol. 1992;262:H17-H22.

15. Ruiz-Meana M, García-Dorado D, González MA, Barrabés JA, Oliveras J, Soler-Soler J. Efecto del edema osmótico durante la reoxigenación sobre la viabilidad celular: estudio en el miocito aislado. Rev Esp Cardiol. 1995;48:266-271.

16. Ruiz-Meana M, García-Dorado D, González MA, Barrabés JA, SolerSoler J. Effect of osmotic stress on sarcolemmal integrity of isolated cardiomyocytes following transient metabolic inhibition. Cardiovasc Res. 1995;30:64-69.

17. Rodríguez-Sinovas A, García-Dorado D, Ruiz-Meana M, SolerSoler J. Enhanced effect of gap junction uncouplers on macroscopic electrical properties of reperfused myocardium. J Physiol. 2004;559: 245-257.

18. Rawanduzy A, Hansen A, Hansen TW, Nedergaard M. Effective reduction of infarct volume by gap junction blockade in a rodent model of stroke. J Neurosurg. 1997;87:916-920.

19. Lin JH, Weigel H, Cotrina ML, et al. Gap-junction-mediated propagation and amplification of cell injury. Nat Neurosci. 1998;1: 494-500.

20. Ruiz-Meana M, García-Dorado D, Hofstaetter B, Piper HM, Soler-Soler J. Propagation of cardiomyocyte hypercontracture by passage of $\mathrm{Na}^{+}$through gap junctions. Circ Res. 1999;85:280-287.

21. Baines CP, Kaiser RA, Purcell NH, et al. Loss of cyclophilin D reveals a critical role for mitochondrial permeability transition in cell death. Nature. 2005;31:658-662.

22. Halestrap AP, Brennerb C. The adenine nucleotide translocase: a central component of the mitochondrial permeability transition pore and key player in cell death. Curr Med Chem. 2003;10:1507-1525.

23. Ruiz-Meana M, Abellán A, Miró-Casas E, Garcia-Dorado D. Opening of mitochondrial permeability transition pore induces hypercontracture in $\mathrm{Ca}^{2+}$ overloaded cardiac myocytes. Basic Res Cardiol. 2007;102: 542-552.

24. Di Lisa F, Bernardi P. A CaPful of mechanisms regulating the mitochondrial permeability transition. J Mol Cell Cardiol. 2009;46:775-780.

25. Heusch G, Boengler K, Schulz R. Inhibition of mitochondrial permeability transition pore opening: the holy grail of cardioprotection. Basic Res Cardiol. 2010;105:151-154.

26. Boengler K, Heusch G, Schulz R. Mitochondria in postconditioning. Antioxid Redox Signal. 2011;14:863-880.

27. Di Lisa F, Canton M, Carpi A, et al. Mitochondrial injury and protection in ischemic pre- and postconditioning. Antioxid Redox Signal. 2011;14: 881-891.

28. Nicolli A, Petronilli V, Bernardi P. Modulation of the mitochondrial cyclosporin A-sensitive permeability transition pore by matrix $\mathrm{pH}$ : evidence that the pore open-closed probability is regulated by reversible histidine protonation. Biochemistry. 1993;32:4461-4465.

29. Duchen MR. Mitochondria and calcium: from cell signalling to cell death. J Physiol. 2000;529:57-68.

30. Hearse DJ, Humphrey SM, Chain EB. Abrupt reoxygenation of the anoxic potassium-arrested perfused rat heart: a study of myocardial enzyme release. J Mol Cell Cardiol. 1973;5:395-407.

31. Lemasters JJ, Bond JM, Chacon E, et al. The pH paradox in ischemiareperfusion injury to cardiac myocytes. EXS. 1996;76:99-114. 
32. Petronilli V, Penzo D, Scorrano L, Bernardi P, Di Lisa F. The mitochondrial permeability transition, release of cytochrome $\mathrm{C}$ and cell death: correlation with the duration of pore openings in situ. J Biol Chem. 2001; 276:12030-12034.

33. Griffiths EJ, Halestrap AP. Mitochondrial non-specific pores remain closed during cardiac ischaemia, but open upon reperfusion. Biochem J. 1995;307:93-98

34. Halestrap AP, Clarke SJ, Javadov SA. Mitochondrial permeability transition pore opening during myocardial reperfusion: a target for cardioprotection. Cardiovasc Res. 2004;61:372-385.

35. Halestrap AP, Pasdois P. The role of the mitochondrial permeability transition pore in heart disease. Biochem Biophys Acta. 2009;1787: 1402-1415.

36. Penzo D, Petronilli V, Angelin A, et al. Arachidonic acid released by phospholipase $\mathrm{A}_{2}$ activation triggers $\mathrm{Ca}^{2+}$-dependent apoptosis through the mitochondrial pathway. J Biol Chem. 2004;279:25219-25225.

37. Scorrano L, Penzo D, Petronilli V, Pagano F, Bernardi P. Arachidonic acid causes cell death through the mitochondrial permeability transition: implications for tumor necrosis factor- $\alpha$ apoptotic signaling J Biol Chem. 2001;276:12035-12040.

38. Shulga N, Pastorino JG. Acyl coenzyme A-binding protein augments Bid-induced mitochondrial damage and cell death by activating $\mu$-calpain. J Biol Chem. 2006;281:30824-30833.

39. Inserte J, Ruiz-Meana M, Rodríguez-Sinovas A, Barba I, Garcia-Dorado D. Contribution of delayed intracellular $\mathrm{pH}$ recovery to ischemic postconditioning protection. Antioxid Redox Signal. 2011;14:923-939.

40. Inserte J, García-Dorado D, Hernando V, Soler-Soler J. Calpain-mediated impairment of $\mathrm{Na}+\mathrm{K}+-\mathrm{ATPase}$ activity during early reperfusion contributes to cell death after myocardial ischemia. Circ Res. 2005;97: 465-473.

41. Green DR, Kroemer G. The pathophysiology of mitochondrial cell death. Science. 2004;305:626-629.

42. Kinnally KW, Antonsson B. A tale of two mitochondrial channels, MAC and PTP, in apoptosis. Apoptosis. 2007;12:857-868.

43. Barrabés JA, García-Dorado D, Mirabet M, et al. Antagonism of selectin function attenuates microvascular platelet deposition and platelet-mediated myocardial injury after transient ischemia. J Am Coll Cardiol. 2005;45:293-299.

44. Mirabet M, García-Dorado D, Ruiz-Meana M, Barrabés JA, Soler-Soler J. Thrombin increases cardiomyocyte acute cell death after ischemia and reperfusion. J Mol Cell Cardiol. 2005;39:277-283.

45. Barrabés JA, Mirabet M, Agulló L, Figueras J, Pizcueta P, GarcíaDorado D. Platelet deposition in remote cardiac regions after coronary occlusion. Eur J Clin Invest. 2007;37:939-946.

46. Balakumar P, Rohilla A, Singh M. Pre-conditioning and postconditioning to limit ischemia-reperfusion injury: what could be the next footstep? Pharmacol Res. 2008;57:403-412.

47. Bland $\mathrm{JH}$, Lowenstein E. Halothane-induced decrease in experimental myocardial ischemia in non-failing canine heart. Anesthesiology. 1976; 45:287-293

48. Warltier DC, al-Wathiqui MH, Kampine JP, Schmeling WT. Recovery of contractile function of stunned myocardium in chronically instrumented dogs is enhanced by halothane or isoflurane. Anesthesiology. 1988;69:552-565.

49. Cason BA, Gamperl AK, Slocum RE, Hickey RF. Anesthetic-induced preconditioning: previous administration of isoflurane decreases myocardial infarct size in rabbits. Anesthesiology. 1997;87:1 182-1190.

50. Landoni G, Bignami E, Oliviero F, Zangrillo A. Halogenated anaesthetics and cardiac protection in cardiac and non-cardiac anaesthesia. Ann Card Anaesth. 2009;12:4-9.

51. De Hert SG. Cardioprotection in anesthesia. Minerva Anestesiol. 2008; 74:259-270.

52. Weinbrenner C, Nelles M, Herzog N, Sarvary L, Strasser RH. Remote preconditioning by infrarenal occlusion of the aorta protects the heart from infarction: a newly identified non-neuronal but PKC-dependent pathway. Cardiovasc Res. 2002;55:590-601.
53. Landoni G, Fochi O, Tritapepe L, Guarracino F. Cardiac protection by volatile anesthetics: a review. Minerva Anestesiol. 2009;75:269-273.

54. Tonkovic-Capin M, Gross GJ, Bosnjak ZJ, Tweddel JS, Fitzpatrick CM, Baker JE. Delayed cardioprotection by isoflurane: role of $\mathrm{K}_{\mathrm{ATP}}$ channels. Am J Physiol Heart Circ Physiol. 2002;283:H61-H68.

55. Pagel PS, Hundetz JA. Delayed cardioprotection by inhaled anesthetics. Cardiothorac Vasc Anesth. 2011;25:1125-1140.

56. Qiao S, Xie H, Wang C, Wu X, Liu H, Liu C. Delayed anesthetic preconditioning protects against myocardial infarction via activation of nuclear factor- $\kappa \mathrm{B}$ and upregulation of autophagy. J Anesth. 2013;27: 251-260.

57. Zaugg M, Lucchinetti E, Uecker M, Pasch T, Schaub MC. Anaesthetics and cardiac preconditioning - part I: signalling and cytoprotective mechanisms. Br J Anaesth. 2003;91:551-565.

58. Zaugg M, Lucchinetti E, Uecker M, Pasch T, Schaub MC. Anaesthetics and cardiac preconditioning - part II: signalling and cytoprotective mechanisms. Br J Anaesth. 2003;91:566-576.

59. De Hert SG, Turani F, Mathur S, Stowe DF. Cardioprotection with volatile anesthetics: mechanisms and clinical implications. Anesth Analg. 2005;100:1584-1593.

60. Sergeev O, da Silva R, Lucchinetti E, et al. Trigger-dependent gene expression profiles in cardiac preconditioning: evidence for distinct genetic programs in ischemic and anesthetic preconditioning. Anesthesiology. 2004;100:474-488.

61. Hanouz JL, Yvon A, Massetti M, et al. Mechanisms of desflurane-induced preconditioning in isolated human tight atria in vitro. Anesthesiology. 2002;97:33-41.

62. $\mathrm{Hu} \mathrm{ZY}$, Liu J. Mechanism of cardiac preconditioning with volatile anaesthetics. Anaesth Intensive Care. 2009;37:532-538.

63. Kunst G, Klein AA. Peri-operative anaesthetic myocardial preconditioning and protection: cellular mechanisms and clinical relevance in cardiac anaesthesia. Anaesthesia. 2015;70:467-482.

64. Uecker M, Da Silva R, Grampp T, Pasch T, Schaub MC, Zaugg M. Translocation of protein kinase $\mathrm{C}$ isoforms to subcellular targets in ischemic and anesthetic preconditioning. Anesthesiology. 2003;99: $138-147$.

65. Obal D, Weber NC, Zacharowski K, et al. Role of protein kinase C- $\varepsilon$ $(\mathrm{PKC}-\varepsilon)$ in isoflurane induced cardioprotection: low, but not high concentrations of isoflurane activate PKC. Br J Anaesth. 2005;94: 166-173.

66. Novalija E, Varadarajan SG, Camara AK, et al. Anesthetic preconditioning: triggering role of reactive oxygen and nitrogen species in isolated hearts. Am J Physiol Heart Circ Physiol. 2002;283:H44-H52.

67. Pravdic D, Hirata N, Barber L, Sedlic F, Bosnjak Z, Bienengraeber M. Complex I and ATP synthase mediate membrane depolarization and matrix acidification by isoflurane in mitochondria. Eur J Pharmacol. 2012;690:149-157.

68. Kowaltowski AJ, Seetharaman S, Paucek P, Garlid KD. Bioenergetic consequences of opening the ATP-sensitive $\mathrm{K}^{+}$channel of heart mitochondria. Am J Physiol Heart Circ Physiol. 2001;280: H649-H657.

69. Sukhodub A, Jovanović S, Du Q, et al. AMP-activated protein kinase mediates preconditioning in cardiomyocytes by regulating activity and trafficking of sarcolemmal ATP-sensitive $\mathrm{K}^{+}$channels. J Cell Physiol. 2007;210:224-236.

70. Budas GR, Sukhodub A, Alessi DR, Jovanović A. 3'Phosphoinositidedependent kinase-1 is essential for ischemic preconditioning of the myocardium. FASEB J. 2006;20:2556-2558.

71. Landoni G, Fochi O, Torri G. Cardiac protection by volatile anaesthetics: a review. Curr Vasc Pharmacol. 2008;6:108-111.

72. De Hert SG, ten Broecke PW, Mertens E, et al. Sevoflurane but not propofol preserves myocardial function in coronary surgery patients. Anesthesiology. 2002;97:42-49.

73. De Hert SG, Cromheecke S, ten Broecke PW, et al. Effects of propofol, desflurane, and sevoflurane on recovery of myocardial function after coronary surgery in elderly high-risk patients. Anesthesiology. 2003;99:314-323. 
74. De Hert SG, Van der Linden PJ, Cromheecke S, et al. Cardioprotective properties of sevoflurane in patients undergoing coronary surgery with cardiopulmonary bypass are related to the modalities of its administration. Anesthesiology. 2004;101:299-310.

75. De Hert S, Vlasselaers D, Barbe R, et al. A comparison of volatile and non-volatile agents for cardioprotection during on-pump coronary surgery. Anaesthesia. 2009;6:953-960.

76. Bignami E, Greco T, Barile L, et al. The effect of isoflurane on survival and myocardial infarction: a meta-analysis of randomized controlled studies. J Cardiothorac Vasc Anesth. 2013;27:50-58.

77. Tritapepe L, Landoni G, Guarracino F, et al. Cardiac protection by volatile anaesthetics: a multicentre randomized controlled study in patients undergoing coronary artery bypass grafting with cardiopulmonary bypass. Eur J Anaesth. 2007;24:323-331.

78. Landoni G, Greco T, Biondi-Zoccai G, et al. Anaesthetic drugs and survival: a Bayesian network meta-analysis of randomized trials in cardiac surgery. Br J Anaesth. 2013;111:886-896.

79. Ballester M, Llorens J, de la Asunción JG, et al. Myocardial oxidative stress protection by sevoflurane vs propofol: a randomized controlled study in patients undergoing off pump coronary artery bypass graft surgery. Eur J Anaesth. 2011;28:874-881.

80. Xia Z, Huang Z, Ansley DM. Large-dose propofol during cardiopulmonary bypass decreases biochemical markers of myocardial injury in coronary surgery patients: a comparison with isoflurane. Anesth Analg. 2006;103:527-532.

81. Piriou V, Mantz J, Goldfarb G, et al. Sevoflurane preconditioning at 1 MAC only provides limited protection in patients undergoing coronary artery bypass surgery: a randomized bi-centre trial. Br J Anaesth. 2007;99:624-623.

82. Garcia-Dorado D, Rodríguez-Sinovas A, Ruiz-Meana M, Inserte J. Protección contra el daño miocárdico por isquemia-reperfusión en la práctica clínica. Rev Esp Cardiol. 2014;67:394-404.

83. Bice J, Baxter GF. Postconditioning signalling in the heart: mechanisms and translatability. Br J Pharmacol. 2015;172:1933-1946.

84. Yellon DM, Hausenloy DJ. Myocardial reperfusion injury. $N$ Engl J Med. 2007;357:1121-1135.

85. Cohen MV, Downey JM. Signalling pathways and mechanisms of protection in pre- and postconditioning: historical perspective and lessons for the future. Br J Pharmacol. 2015;172:1913-1932.

86. Jivraj N, Liew F, Marber M. Ischaemic postconditioning: cardiac protection after the event. Anaesthesia. 2015;70:598-612.

87. Inserte J, Barba I, Hernando V, García-Dorado D. Delayed recovery of intracellular acidosis during reperfusion prevents calpain activation and determines protection in postconditioned myocardium. Cardiovasc Res. 2009;81:116-122.

88. Ong SB, Dongworth RK, Cabrera-Fuentes HA, Hausenloy DJ. Role of the MPTP in conditioning the heart: translatability and mechanism. Br J Pharmacol. 2015;172:2074-2084.

89. Lemoine S, Tritapepe L, Hanouz JL, Puddu PE. The mechanisms of cardioprotective effects of desflurane and sevoflurane at the time of reperfusion: anaesthetic postconditioning potentially translatable to humans? Br J Anaesth. 2016;116:456-475.

90. Kaminski K, Bonda T, Korecki J, Musial WJ. Oxidative stress and neutrophil activation: the two keystones of ischemia/reperfusion injury. Int J Cardiol. 2002;86:41-59.

91. Xia Z, Li H, Irwin MG. Myocardial ischaemia reperfusion injury: the challenge of translating ischaemic and anaesthetic protection from animal models to humans. Br J Anaesth. 2016;117 Suppl 2:ii44-ii62.

92. Yu P, Zhang J, Yu S, et al. Protective effect of sevoflurane postconditioning against cardiac ischemia/reperfusion injury via ameliorating mitochondrial impairment, oxidative stress and rescuing autophagic clearance. PLoS One. 2015;10:e0134666.

93. Hausenloy DJ, Yellon DM. Survival kinases in ischemic preconditioning and postconditioning. Cardiovasc Res. 2006;70:240-253.

94. Luo W, Li B, Lin G, Huang R. Postconditioning in cardiac surgery for tetralogy of Fallot. J Thorac Cardiovasc Surg. 2007;133: 1373-1374.
95. Luo W, Li B, Chen R, Huang R, Lin G. Effect of ischemic postconditioning in adult valve replacement. Eur J Cardiothorac Surg. 2008;33:203-208.

96. Wagner R, Piler P, Gabbasov Z, et al. Adjuvant cardioprotection in cardiac surgery: update. Biomed Res Int. 2014;2014:808096.

97. Hausenloy DJ, Boston-Griffiths E, Yellon DM. Cardioprotection during cardiac surgery. Cardiovasc Res. 2012;94:253-265.

98. Steurer MP, Steurer MA, Baulig W, et al. Late pharmacologic conditioning with volatile anesthetics after cardiac surgery. Crit Care. 2012;16:R191.

99. Lange M, Redel A, Lotz C, et al. Desflurane-induced postconditioning is mediated by beta-adrenergic signaling: role of $\beta 1$ - and $\beta 2$-adrenergic receptors, protein kinase A, and calcium/calmodulin-dependent protein kinase II. Anesthesiology. 2009;110:516-528.

100. Lemoine $\mathrm{S}$, Buléon $\mathrm{C}$, Rouet $\mathrm{R}$, et al. Bradykinin and adenosine receptors mediate desflurane induced postconditioning in human myocardium: role of reactive oxygen species. BMC Anesthesiol. 2010;10:12.

101. Lemoine S, Durand C, Zhu L, et al. Desflurane-induced postconditioning of diabetic human right atrial myocardium in vitro. Diabetes Metab. 2010;36:21-28.

102. Hausenloy DJ, Yellon DM. New directions for protecting the heart against ischaemia-reperfusion injury: targeting the reperfusion injury salvage kinase (RISK)-pathway. Cardiovasc Res. 2004;61:448-460.

103. Sanada S, Komuro I, Kitakaze M. Pathophysiology of myocardial reperfusion injury: preconditioning, postconditioning, and translational aspects of protective measures. Am J Physiol Heart Circ Physiol. 2011; 301:H1723-H1741.

104. Abdul KS, Jovanović S, Sukhodub A, Du Q, Jovanović A. Upregulation of cardioprotective SUR2A by sub-hypoxic drop in oxygen. Biochim Biophys Acta. 2014;1843:2424-2431.

105. Tai W, Shi E, Yan L, Jiang X, Ma H, Ai C. Diabetes abolishes the cardioprotection induced by sevoflurane postconditioning in the rat heart in vivo: roles of glycogen synthase kinase-3 $\beta$ and its upstream pathways. J Surg Res. 2012;178:96-104.

106. Drenger B, Ostrovsky IA, Barak M, et al. Diabetes blockade of sevoflurane postconditioning is not restored by insulin in the rat heart: phosphorylated signal transducer and activator of transcription 3-and phosphatidylinositol 3-kinase-mediated inhibition. Anesthesiology. 2011;114:1364-1372.

107. Lin J, Wang T, Li Y, et al. N-acetylcysteine restores sevoflurane postconditioning cardioprotection against myocardial ischemia-reperfusion injury in diabetic rats. J Diabetes Res. 2016;2016:9213034.

108. Guarracino F, Landoni G, Tritapepe L, et al. Myocardial damage prevented by volatile anesthetics: a multicenter randomized controlled study. J Cardiothorac Vasc Anesth. 2006;20:477-483.

109. Kawamura T, Kadosaki M, Nara N, et al. Effects of sevoflurane on cytokine balance in patients undergoing coronary artery bypass graft surgery. J Cardiothorac Vasc Anesth. 2006;20:503-508.

110. Conzen PF, Fischer S, Detter C, Peter K. Sevoflurane provides greater protection of the myocardium than propofol in patients undergoing off-pump coronary artery bypass surgery. Anaesthesiology. 2003;99: 826-833.

111. Guerrero-Orriach JL, Aliaga MR, Ortega MG, Navarro MR, Arce IN, Mañas JC. Sevoflurane in intraoperative and postoperative cardiac surgery patients: our experience in intensive care unit with sevoflurane sedation. Curr Pharm Des. 2013;19:3996-4002.

112. Guerrero-Orriach JL, Ortega MG, Aliaga MR, et al. Prolonged sevoflurane administration in the off-pump coronary artery bypass graft surgery: beneficial effects. J Crit Care. 2013;28:879.e13-e18.

113. Soro M, Gallego L, Silva V, et al. Cardioprotective effect of sevoflurane and propofol during anaesthesia and the postoperative period in coronary bypass graft surgery: a double-blind randomised study. Eur J Anaesthesiol. 2012;29:561-569.

114. Hellström J, Owall A, Bergström J, Sackey PV. Cardiac outcome after sevoflurane versus propofol sedation following coronary bypass surgery: a pilot study. Acta Anaesthesiol Scand. 2011;55:460-467. 
115. Perelli M, Pasquale P, Penna C. Ischemia/reperfusion injury and cardioprotective mechanisms: role of mitochondria and reactive oxygen species. World J Cardiol. 2011;3:186-200.

116. Bignami E, Landoni G, Crescenzi G, et al. Role of cardiac biomarkers (troponin I and CK-MB) as predictors of quality of life and long-term outcome after cardiac surgery. Ann Card Anaesth. 2009;12:22-26.
117. Bonnefoy E, Filley S, Kirkorian G, et al. Troponin I, troponin T, or creatine kinase-MB to detect perioperative myocardial damage after coronary artery bypass surgery. Chest. 1998;114:482-486.

\section{Publish your work in this journal}

Drug Design, Development and Therapy is an international, peerreviewed open-access journal that spans the spectrum of drug design and development through to clinical applications. Clinical outcomes, patient safety, and programs for the development and effective, safe, and sustained use of medicines are the features of the journal, which has also been accepted for indexing on PubMed Central. The manuscript management system is completely online and includes a very quick and fair peer-review system, which is all easy to use. Visit http://www.dovepress.com/testimonials.php to read real quotes from published authors.

Submit your manuscript here: http://www.dovepress.com/drug-design-development-and-therapy-journal 